IZA DP No. 5049

Strategic Sophistication of Adolescents:

Evidence from Experimental Normal-Form Games

Simon Czermak

Francesco Feri

Daniela Rützler

Matthias Sutter

July 2010 


\title{
Strategic Sophistication of Adolescents: Evidence from Experimental Normal-Form Games
}

\author{
Simon Czermak \\ University of Innsbruck
}

Francesco Feri

University of Innsbruck

Daniela Rützler

University of Innsbruck

\author{
Matthias Sutter \\ University of Innsbruck, \\ University of Gothenburg and IZA
}

Discussion Paper No. 5049

July 2010

IZA

P.O. Box 7240

53072 Bonn

Germany

Phone: +49-228-3894-0

Fax: +49-228-3894-180

E-mail: iza@iza.org

\begin{abstract}
Any opinions expressed here are those of the author(s) and not those of IZA. Research published in this series may include views on policy, but the institute itself takes no institutional policy positions.

The Institute for the Study of Labor (IZA) in Bonn is a local and virtual international research center and a place of communication between science, politics and business. IZA is an independent nonprofit organization supported by Deutsche Post Foundation. The center is associated with the University of Bonn and offers a stimulating research environment through its international network, workshops and conferences, data service, project support, research visits and doctoral program. IZA engages in (i) original and internationally competitive research in all fields of labor economics, (ii) development of policy concepts, and (iii) dissemination of research results and concepts to the interested public.
\end{abstract}

IZA Discussion Papers often represent preliminary work and are circulated to encourage discussion. Citation of such a paper should account for its provisional character. A revised version may be available directly from the author. 
IZA Discussion Paper No. 5049

July 2010

\section{ABSTRACT \\ Strategic Sophistication of Adolescents: Evidence from Experimental Normal-Form Games ${ }^{*}$}

We examine the strategic sophistication of adolescents, aged 10 to 17 years, in experimental normal-form games. Besides making choices, subjects have to state their first- and secondorder beliefs. We find that choices are more often a best reply to beliefs if any player has a dominant strategy and equilibrium payoffs are not too unequal. Using a mixture model we can estimate for each subject the probability to be any of eight different strategic and nonstrategic types. The econometric estimation reveals that older subjects are more likely to eliminate dominated strategies, and that subjects with good math grades are more strategic.

JEL Classification: $\quad$ C72, C91

Keywords: strategic thinking, beliefs, experiment, age, adolescents

Corresponding author:

Matthias Sutter

Department of Public Finance

University of Innsbruck

Universitaetsstrasse 15

A-6020 Innsbruck

Austria

E-mail: matthias.sutter@uibk.ac.at

\footnotetext{
* We would like to thank Lise Vesterlund and participants at the AEA-Meetings 2010 in Atlanta for helpful comments. We are indebted to Director Gerhard Sailer of the "Öffentliches Gymnasium der Franziskaner Hall" for making this study possible. Financial support from the Hypo Tirol Bank AG (Forschungsförderungspreis der Hypo Tirol) is gratefully acknowledged.
} 


\section{Introduction}

Standard game theory is the fundamental pillar of research in economics, and more generally in the social sciences, since it provides a tool to analyze strategic interaction, like interaction in markets, bargaining, or in social dilemma situations. An important implication of game theory is the assumption that subjects are sophisticated in a sense that they take other subjects' incentives and the structure of a game into account before deciding on their strategy. This is called strategic sophistication. By now, there exists a broad experimental literature on the strategic sophistication of individual decision makers in normal-form games (see, e.g., Stahl and Wilson, 1994, 1995; Haruvy, Stahl and Wilson, 1999; Costa-Gomes, Crawford and Broseta, 2001; Weizsäcker, 2003; Bhatt and Camerer, 2005; Crawford and Iriberri, 2007; Costa-Gomes and Weizsäcker, 2008; Fehr, Kübler and Danz, 2009; Rey-Biel, 2009; Sutter, Czermak and Feri, 2010a). This literature studies the degree of strategic sophistication. In a nutshell, the bottom line of research is the fact that strategic sophistication is often limited. Most importantly, many subjects make decisions without taking into account the incentives and the rationality of the other players (Costa-Gomes et al., 2001, Weizsäcker, 2003). Another important limitation is the frequently observed failure of subjects to best respond to their own stated beliefs. For instance, Costa-Gomes and Weizsäcker (2008) report such a failure to happen in about fifty percent of cases. While the literature on strategic sophistication has developed models to explain this surprisingly large degree of bounded rationality (see CostaGomes and Crawford, 2006, or Costa-Gomes and Weizsäcker, 2008, for a discussion of models and new approaches), it has remained silent on the development of strategic sophistication with age. All previous studies have relied on university students in their early and middle 20ies, however nothing is known yet whether strategic sophistication changes with age. Providing evidence to address the latter question is the main purpose of this paper. In a survey of simple bargaining experiments Camerer (2003, p. 66) notes that in ultimatum and dictator games children are "closer to the self-interest prediction of game theory than virtually any adult population”. It is an open question whether this statement applies also more generally to strategic sophistication in normal form games, and in particular when subjects do not only have to make decisions (as in the games surveyed in Camerer, 2003), but are also asked to state beliefs about their opponent's choices and beliefs.

In the experiment reported here, we let 196 adolescents, aged 10 to 17 years, make decisions in 18 different normal-form games that have been designed by Costa-Gomes et al. 
(2001) to study strategic sophistication. In addition to asking for choices, we elicited first order beliefs about the opponent's choice, and second-order beliefs about the opponent's first order belief. Eliciting higher-order beliefs allows us to examine not only the decision maker's consistency (where consistency means that choices are a best reply to first-order beliefs), but also the opponent's expected consistency, i.e. how subjects perceive the rationality of their opponents by checking whether first-order beliefs are best responses to second-order beliefs. In particular, our analysis will focus on the following aspects of strategic sophistication: (i) the relative frequency of choosing the strategy which is part of a game's Nash equilibrium; (ii) the factors that increase - or decrease - a subject's probability to play the equilibrium strategy and to expect the opponent to do the same, i.e., the determinants of standard game theoretic behavior; (iii) the distribution of eight different decision making types (strategic and non-strategic) in our sample. The latter issue is addressed by applying the maximum likelihood error-rate analysis developed by Costa-Gomes et al. (2001). It is a mixture model in which each decision maker's type is drawn from a common prior distribution over eight different strategic and non-strategic types and the type is assumed to be constant in all 18 games.

In the experiment, we find that (i) adolescents play the Nash strategy in about $45 \%$ of cases. This relative frequency of equilibrium play is well in the range of $40 \%$ to $50 \%$ which is the typical finding in previous studies with adults (e.g., Costa-Gomes and Weizsäcker, 2008; Sutter, Czermak and Feri, 2010). In about 60\% of cases our subjects choose a best response to their own first-order belief. This is slightly higher than what is observed with university students (Costa-Gomes and Weizsäcker, 2008; Sutter et al., 2010a). The expected consistency of opponents (by matching first- and second-order beliefs) is at a lower level of around $50 \%$.

The analysis of the determinants of the standard game theoretic behavior shows that (ii) the combination of playing the Nash strategy and expecting the opponent to do the same becomes more likely if any of the two players has a dominant strategy (i.e., if the level of a game's complexity is low), if a maximax strategy ${ }^{1}$ contains a high risk of losing payoffs, and if payoffs in equilibrium are rather equal for both players. The latter finding indicates clearly that social preferences affect standard game-theoretic reasoning.

Applying the mixture model of Costa-Gomes et al. (2001), we find that (iii) the majority of adolescents can be classified as non-strategic decision makers and the modal type is a nonstrategic optimistic type (which plays the strategy that maximizes the maximum possible

\footnotetext{
${ }^{1}$ It is the strategy by which a subject - in the most favorable case - could earn the highest possible payoff.
} 
payoff). While we do not find a significant effect of age on the share of subjects classified as belonging to any of five different types of strategic decision making, we find that the elimination of dominated strategies becomes more likely with increasing age. Hence, detecting dominance relationships gets more frequent with older subjects. It is also interesting to note that girls are significantly more likely to eliminate dominated strategies than boys. Not surprisingly, we also find a relation between math grades and strategic decision making. Subjects with better math grades are more likely to be classified as strategic.

Although the main focus of our paper is to contribute to the literature on strategic sophistication, it is also related to the literature on the decision making of children and teenagers. The latter literature has been pioneered mainly by Bill Harbaugh and Kate Krause and they have shown that in straightforward bargaining games children are obviously able to employ simple forms of strategic considerations. This becomes particularly clear when comparing children's behavior in ultimatum and dictator games, where for strategic reasons (i.e., fear of rejection) offers are higher in the ultimatum than the dictator game (see Harbaugh, Krause and Liday, 2003a). ${ }^{2}$ While it seems beyond doubt that children and adolescents are able to make strategic inferences and act accordingly in simple economic games, the existing literature on the decision making of children and adolescents has not studied the extent of strategic sophistication (including not only an examination of choices, but also of first- as well as second-order beliefs) in childhood and adolescence. The literature also lacks an estimation of decision-making types on the level of an individual subject. In our paper we can classify subjects into eight different strategic and non-strategic types and can check how socio-demographic factors influence a subject's type. This is intended to provide a deeper analysis of strategic sophistication of adolescents than has been achieved previously.

The rest of the paper is organized as follows. In section 2 we present the experimental design, including the description of the normal-form games used in the experiment, the experimental treatments and procedure. In section 3 we report our experimental results, beginning with a descriptive analysis of aggregate data, continuing with regressions that identify factors promoting standard game theoretic behavior, and concluding with the estimation of individual subjects' most likely decision making types and the impact of sociodemographics on these types. Section 4 concludes the paper.

\footnotetext{
${ }^{2}$ Several other papers study the behavior of children and teenagers in simple interactive games, like public goods games (Harbaugh and Krause, 2000), trust games (Harbaugh et al., 2003b; Sutter and Kocher, 2007), or ultimatum games (Murnighan and Saxon, 1998; Sutter 2007).
} 


\section{Experimental design}

\subsection{The 18 normal-form games}

Our experimental design is based on the 18 normal-form games used by Costa-Gomes et al. (2001) to study strategic sophistication (see Figure 1). These 18 games include 8 pairs of isomorphic games that are identical for row and column players except for transformation of player roles and small, uniform payoff shifts. One can distinguish two types of games with respect to the existence of a dominant strategy. There are 10 "D"-games in which one player has a strictly dominant strategy and 8 "ND"-games in which no player has a dominant strategy. In all games there is a unique pure Nash equilibrium that is Pareto-dominated by another strategy combination of row and column players. The games can also be classified according to the number of rounds of iterated pure-strategy dominance that row and column players need to identify the equilibrium strategy. This refers to a game's complexity. In Dgames the number of rounds a player requires to reach his own equilibrium choice is either 1 or 2, while in ND-games the corresponding number of rounds may be 2, 3 or infinite. Figure 1 indicates all games' types, complexities and the order with which the specific games were presented to participants. $^{3}$

Figure 1 about here

\subsection{Decisions and payment}

Each game was played only once and in each game subjects had to make three different decisions in the following sequence: ${ }^{4}$

- Choice: For each given game each player had to choose one of the available strategies.

- First-order belief (FOB): Subjects had to state their belief about the opponent's action.

\footnotetext{
${ }^{3}$ This information can be found in the upper left and right corner of each game in Figure 1 . The order of games in the experiment is indicated by "game \# $\mathrm{x}$ ", with $\mathrm{x} \in\{1, \ldots, 18\}$. (D) refers to D-games and (ND) refers to ND-games. Numbers in the brackets indicate a game's complexity for the row and column player, where [xR, $\mathrm{yR}$ ] denotes the number of rounds needed for row (x) and column player (y).

${ }^{4}$ Games were presented to all participants in the same order as in Costa-Gomes et al. (2001) and in a way that they saw themselves as a row player. The transformation of the column players' perspective didn't have any influence on the characteristics of the games and was intended to avoid any influence of the kind of presentation on behavior.
} 
- Second-order belief (SOB): Subjects were asked for their belief about the opponent's first-order belief. This means they had to indicate the strategy they think they are expected to play by the opponent player.

In sum, each subject was taking a total of 54 decisions during the whole experiment. In order to suppress learning and reputation formation there was no feedback until the experiment was finished. All details of this procedure were common knowledge to all participants.

At the end of the experiment one of the 18 games was randomly determined for a subject's payment. For this purpose each subject was asked to draw a card from a deck of cards showing numbers from 1 to 18. The drawn number determined the game that was relevant for payment. In a next step the subject received full information about his/her own and the opponent's choice, first- and second-order belief in the particular game. A second card to be drawn by a subject then determined whether choices (card A), first-order beliefs (card B) or second-order beliefs (card C) were paid.

Payments in the experiment were made contingent on the age of participants, calibrated on the average weekly pocket money. Based on a survey data from the respective school, we knew that subjects aged 14 to 17 years (grades 9 and 11) receive on average slightly more than twice as much weekly pocket money as subjects aged 10 to 13 years (grades 5 and 7). Accordingly we scaled the payoffs in the following way. If a subject was paid for his/her choice, we paid 20 Euro-Cents per experimental point in grades 9 and 11, and we paid 10 Euro-Cents per point in grades 5 and 7. If subjects were paid for their first-order or secondorder belief $9^{\text {th }}$ graders and $11^{\text {th }}$ graders received 10 Euros if their belief was correct, while $5^{\text {th }}$ and $7^{\text {th }}$ graders got 5 Euros for a correct belief, but zero otherwise. Note that all subjects received a show up fee, which was 4 Euros in grades 9 and 11, and 2 Euros in grades 5 and 7.

The all-or-nothing feature for paying beliefs was intended to make the decisions on firstand second-order beliefs as salient as possible. Eliciting point beliefs - instead of a probability distribution of beliefs over different actions - may be criticized because it might make it difficult to check the consistency of actions and beliefs. While eliciting a probability distribution of beliefs over actions may look like a remedy to this problem, asking for a probability distribution has also problems with checking consistency when first- and secondorder beliefs (one of our central design-features) are involved. The reason is that it is possible that a subject's first-order belief - stated as a probability distribution - fails to be a best response to the second-order belief - also expressed as a probability distribution - although 
both beliefs are optimally stated. ${ }^{5}$ Given the latter problems with checking consistency, we have opted for asking for point beliefs. This design choice is additionally motivated by the following practical considerations. Explaining the concept of a probability distribution and asking adolescents of age ten to seventeen to express their beliefs in an incentive compatible payment scheme like the quadratic scoring rule would have been extremely demanding for teenagers. Given the relatively high number of decisions (54) we also opted for eliciting point beliefs in order to keep the duration of the experiment shorter.

\subsection{Experimental procedure}

The experiment was run at the "Öffentliches Gymnasium der Franziskaner Hall”, a public high school located $5 \mathrm{~km}$ east of Innsbruck, the capital of the state of Tyrol in Austria. This school teaches children in 8 different grades, in Anglo-Saxon terminology grades 5 to 12 . We conducted the experiment in two classes each in $5^{\text {th }}$ grade (10- to 11 -year olds), $7^{\text {th }}$ grade (12to 13 -year olds), $9^{\text {th }}$ grade (14- to 15 -year olds), and $11^{\text {th }}$ grade (16- to 17 -year olds). The sessions in both classes of a given grade were always run simultaneously in two separate rooms in order to avoid any potential dissemination of information. Students were never matched within their own class, but with one student from the other class. This procedure was common knowledge. Subjects were also informed that the identities would be kept strictly confidential toward other participants. In order to guarantee also anonymity within a class, we used sliding walls between subjects so that they could not observe other subjects' decisions.

Each session was started with an extensive description and training of the game (see supplementary material). Questions were answered in private. Before the start of the experiment, each participant had to answer a control questionnaire that checked the understanding of how decisions or beliefs mapped into payoffs. Five subjects (out of 196 in the beginning) did not answer all questions correctly. They are excluded in the following,

\footnotetext{
${ }^{5}$ We would like to thank Georg Weizsäcker for drawing our attention to the problems of inconsistency between first- and second-order beliefs even for situations in which probability distributions are elicited. To illustrate the main intuition, consider the two following cases: (i) Subject A expects subject B to have two different first-order beliefs such that by $50 \%$ subject B expects subject A to play his first strategy for sure and by $50 \%$ he expects subject A to play his second strategy for sure. (ii) Subject A expects subject B to think that subject A plays any of his first two strategies by $50 \%$. In both cases an optimally reported second order belief assigns a $50 \%$ probability to both strategies. Depending on situation (i) or (ii) prevailing, it is possible that subject B's best reply differs between (i) and (ii). As a consequence, subject A's first-order belief can differ, and if case (i) is the true second-order belief, it is possible that the optimal first-order belief for subject A is not a best reply to the optimal second-order belief (if we implicitly assume case (ii)). Given that even with probability distributions such a problem can occur - and not only when asking for point beliefs - we have opted for the easier way of eliciting point beliefs.
} 
yielding 191 subjects for the subsequent analysis. The experiment itself was run with paper and pen. We handed out the three decision sheets for each game (for choices, first- and second-order beliefs) game by game. That means that subjects had to make all three decisions for a particular game before proceeding to the next game. In total, each session lasted 2.5 hours. The average earnings were about 7 Euros for subjects in $5^{\text {th }}$ and $7^{\text {th }}$ grade, and 14 Euros for those in $9^{\text {th }}$ and $11^{\text {th }}$ grade. Our incentives can be considered as pretty salient because the average earnings were slightly higher than the average weekly pocket money of around 5 Euros for 10- to 13-year-olds, and 13 Euros for 14- to 17-year-olds.

\section{Experimental results ${ }^{6}$}

\subsection{Choices, first- and second-order beliefs}

Table 1 reports in the upper panel the relative frequencies for own choices, in the middle and lower panel for first-order, respectively second-order, beliefs. The first column considers all 18 games, while columns two and three present separate data for $\boldsymbol{D}$-games and $\mathbf{N D}$-games. We denote the strategy that leads to the Nash-equilibrium by "Nash", the strategy that would yield an outcome that Pareto-dominates the Nash-equilibrium by "Pareto" and other strategies by "Other".

\section{Table 1 about here}

We note from Table 1 that Nash is played in $45 \%$ of cases. As becomes clear from Table S1 in the supplementary material the relative frequency of playing Nash is, in the aggregate, roughly the same in all four grades in which we ran the experiment. ${ }^{7}$ Not surprisingly, the relative frequency of Nash is clearly higher in $\boldsymbol{D}$-games (62\%) than in $\mathbf{N D}$-games (24\%).

\footnotetext{
${ }^{6}$ All analyses presented in the results section are based on pooled data of row and column players. This is justified since there are 16 isomorphic games in the set of 18 games and all decision tasks were presented in a way that players saw themselves as row players. Note that all results reported here would also go through if we concentrated only on the 16 isomorphic games.

${ }^{7}$ If we assumed that subjects took their decisions randomly, the expected relative frequency of observing Nash equilibrium choices, first order beliefs or second order beliefs would be $43 \%$. A comparison of the distribution of actually observed relative frequencies of playing Nash - based on the level of individuals - and the distribution of theoretically expected ones in case of random play reveals that decisions are significantly different from random, though (Kolmogorov-Smirnov one sample test, $p<0.01$ ).
} 
Looking at first- and second-order beliefs we note that the relative frequency of the Nash strategy is about 10 percentage points smaller according to beliefs than with actual play. ${ }^{8}$

\section{Table 2 about here}

Table 2 shows how the level of a game's complexity - defined by the type of the underlying game and the required rounds of iterated pure-strategy dominance to identify the equilibrium choice - affects choices and beliefs. It reports the frequencies of chosen strategies in five different categories of "decision-complexity": $\boldsymbol{D}$-games with either one or two rounds of iterated pure-strategy dominance and $N D$-games with either two, three or an infinite number of rounds. The first column in the upper panel shows that in games with a dominant strategy, players having a dominant strategy play Nash in $85 \%$ of cases. ${ }^{9}$ The likelihood of playing Nash is drastically reduced once a decision maker has no longer a dominant strategy (see the four right most columns in Table 2). The middle and lower panel of Table 2 refers to first- and second-order beliefs. While Nash remains at or above $80 \%$ in the first column, the other columns show that Nash is considerably less often expected (both in first- and secondorder beliefs) than actually played. We summarize the findings in this subsection as follows:

Result 1: Overall, the equilibrium strategy is chosen in about $45 \%$ of cases. First- and second-order beliefs of equilibrium play are significantly less frequent by roughly 10 percentage points. The relative frequency of playing Nash decreases with a game's complexity, i.e., the number of rounds of iterated pure-strategy dominance needed to identify the equilibrium.

\subsection{Consistency of choices and beliefs}

Let us define a player's “own consistency” as the relative frequency of choices that are a best reply to her own first-order beliefs and the "opponent's expected consistency" as the relative frequency with which a player's first-order beliefs are a best reply to her second-order beliefs. Basically the latter definition determines a player's first-order belief about the opponent's consistency.

\footnotetext{
${ }^{8}$ This pattern is consistent with a model of noisy introspection by Goeree and Holt (2004) in which they predict more noise - and hence less equilibrium play - with higher-order beliefs than with actual play.

${ }^{9}$ Table S2 in the supplementary material indicates that this relative frequency, and most others discussed in Table 2, are very similar in the aggregate if we consider each grade $\left(5^{\text {th }}\right.$ to $\left.11^{\text {th }}\right)$ separately.
} 
Table 3 reports in the upper part for own consistency that in $63 \%$ of all cases players' choices are a best-reply to their first-order (point) belief. ${ }^{10}$ The own consistency is higher in D-games than in ND-games, hinting at the influence of dominant strategies on consistent behavior. The next subsection will provide more details on this issue. The opponent's expected consistency is (significantly ${ }^{11}$ ) lower than the own consistency, with first-order beliefs being a best reply to second-order beliefs in 53\% of cases. Again, the consistency is higher in $\mathbf{D}$-games than in ND-games.

Table 3 and Table 4 about here

Next we consider in more detail the two most frequent types of consistency that appear in the data. One type coincides with the standard game theoretic behavior and is a straightforward combination of playing Nash and expecting the opponent to play Nash as well. We denote this type as "Nash-consistency" (Nash-CON). The other type is a combination of a player's choice and first-order belief that yields the maximal available payoff for the player. We call this the "Maximum-consistency" (Max-CON). An important feature of our games is that Max-CON cannot coincide with Nash-CON. Table 4 reports the relative frequencies of Nash-CON and Max-CON. For a players' own consistency (see upper part) we can see that Nash-CON is much more frequent in $\boldsymbol{D}$-games than in the $\mathbf{N D}$-games (24\% vs. $6 \%$; $p<0.05$, two-sided Wilcoxon signed rank test). ${ }^{12}$ However, Max-CON is more frequently observed, indicating that subjects are pretty optimistic (by expecting the highest possible payoffs from their combination of choices and first-order beliefs). Section 3.4 will present more detailed estimations on players' types. We summarize the findings in this subsection as follows:

Result 2: Choices are a best reply to first-order beliefs in 63\% of cases, while first-order beliefs are a best reply to second-order beliefs in only 53\% of cases. Most of the time, consistent choices and beliefs are of the Max-CON type, meaning that subjects expect the

\footnotetext{
${ }^{10}$ Comparisons of theoretically expected relative frequencies of being consistent in the case of random play and actually observed relative frequencies of being consistent show that the null-hypothesis of randomness in consistency needs to be rejected ( $p<0.01$; both for own consistency and the opponent's expected consistency; Kolmogorov-Smirnov one-sample tests).

${ }^{11} p<0.05$, two-sided Wilcoxon-signed rank tests for all pairwise comparisons.

${ }^{12}$ Comparisons of the theoretically expected distribution of the relative frequencies of being Nash-CON in the case of random play and the actually observed distribution show that the null-hypothesis of randomness in Nash-consistency needs to be rejected ( $p<0.05$; both for own Nash-consistency and the opponent's expected Nash-consistency; Kolmogorov-Smirnov one-sample tests).
} 
maximal payoffs. Nash-consistency (of playing and expecting the opponent to play Nash) is less frequent with $16 \%$ on average, and more likely in D-games than in ND-games.

\subsection{The determinants of consistency-type Nash-CON}

Standard game theory would predict to observe only Nash consistency. The findings summarized in the previous result, however, motivate an analysis of which factors drive standard game-theoretic behavior and beliefs - and which ones prevent it. Table 5 reports the results of a probit estimation of Nash-CON on various factors which we will explain in the following. In our probit estimation standard errors are clustered on the decision maker, since each decision maker had to make decisions in all 18 games.

\section{Table 5 about here}

The first two independent variables in Table 5 consider the existence of a dominant strategy for the player herself (“dominant strategy”) and the existence of a dominant strategy for the opponent player (“opponent dominant strategy”). Both variables have a significantly positive coefficient, indicating that Nash-CON becomes more likely if any player has a dominant strategy (which is the case in $\mathbf{D}$-games). The next three independent variables are dummies for the different grades that were included in our experiment, with $5^{\text {th }}$ graders as the benchmark. ${ }^{13}$ None of these dummies for age is significant here, showing that standard game theoretic reasoning (i.e., playing and expecting Nash) does not change in the period of age covered in our subject pool.

The final three variables in Table 5 relate to the magnitude and distribution of payoffs in a certain game. The variable "risk with maxstrategy" captures the money at risk when a player chooses the strategy that could yield the highest possible payoff instead of playing Nash. This variable measures the absolute difference between a player's payoff in the Nash-equilibrium and the player's payoff in case he chooses the strategy in which the game's highest payoff is possible while the opponent played Nash. The estimation shows that Nash-CON gets significantly more likely when deviating from the Nash strategy is associated with higher

\footnotetext{
${ }^{13}$ Note that interacting the dummies for the different grades with the other independent variables has not produced any significant interaction effects, nor has it changed the main results presented in Tables 5 and 6.
} 
potential reductions in payoffs. The final two variables cover distributional preferences by examining the influence of inequality aversion in the Nash equilibrium on the consistency of decisions. Given that Fehr and Schmidt (1999) show that subjects respond differently to advantageous and disadvantageous inequality, we distinguish between "advantageous inequality in Nash” (defined as max \{own payoff - opponent's payoff in Nash, 0\}) and “disadvantageous inequality in Nash” (defined as max \{opponent's payoff - own payoff in Nash, 0\}). These variables have a negative, but insignificant, impact on the likelihood to observe Nash-CON decisions.

\section{Table 6 about here}

In Table 6 we present a probit regression which is similar to the one in Table 5, but takes as the dependent variable a player's expectation about the opponent being a Nash-CON-type. Basically, we find the same significant relationships as in Table 5, for which reason we do not repeat the description of the directional influence of the independent variables. There are two exceptions, though. We find a significantly negative dummy for $7^{\text {th }}$ graders, indicating that children in $7^{\text {th }}$ grade expect their opponents to be less likely of the Nash-CON-type than $5^{\text {th }}$ graders (as well as $9^{\text {th }}$ graders, as a Wald-test shows). Furthermore, "advantageous inequality in Nash" (in favor of the opponent, as this variable is defined from the opponent's point of view) is significant and reduces the likelihood with which a player expects the opponent to be of the Nash-CON-type. This suggests that players expect their opponents to care for inequality that favors the opponent, but harms the player himself. Hence, a player expects opponents to be less likely of the Nash-CON-type when playing Nash would result in disadvantageous inequality for the player.

Result 3: The main determinants for Nash-consistency are the existence of a dominant strategy (for the player herself or the opponent) and relatively larger losses from deviating from Nash. Concerning the opponent's expected Nash-consistency we find in addition inequality aversion to be a significant hindrance of expecting Nash-consistency. Hence, distributional preferences affect the degree of standard game-theoretic rationality. 


\subsection{Estimation of strategic and non-strategic types}

In the following we present a maximum likelihood error-rate analysis of players' choices following the framework of Costa-Gomes et al. (2001). It is a mixture model in which each player's type is drawn from a common prior distribution over eight types and where the type is assumed to be constant for all 18 games. The eight different types can be classified into non-strategic and strategic types and are defined as follows: ${ }^{14}$

Non-strategic types: (1) An altruistic type makes an attempt to maximize the sum of both players' payoffs, implicitly assuming that the opponent is also altruistic (see CostaGomes et al., 2001). Note that efficiency-loving would probably be a more appropriate term for such a type. Hence, we will call this type altruistic/efficiency-loving. (2) A pessimistic type plays maximin, thus is taking choices that secure him the best of all worst outcomes. (3) An optimistic type chooses the strategy that maximizes the maximum possible payoff, thus ignoring the incentives of the opponent player. As noted by Costa-Gomes et al. (2001), it is impossible to distinguish an optimistic type from a naïve type in our 18 games. A naïve type assigns equal probabilities to the opponent's strategies and best responds to this naïve belief. While a naïve type might reflect strategic decision making with diffuse beliefs, Costa-Gomes et al. (2001) describe naive types as non-strategic. We follow their approach, but talk about optimistic types, which are non-strategic for sure.

Strategic types: (4) Type $L 2$ is choosing a best response to optimistic types. (5) Type D1 plays best reply to a uniform prior over the opponent's remaining strategies after applying one step of deleting strategies that are dominated by pure strategies. (6) Type D2 goes one step further in deleting dominated strategies. After applying two steps of deleting dominated strategies he chooses a best reply to the opponent's remaining strategies. (7) An equilibrium type takes equilibrium choices (which are unique in our games). (8) Choices of a sophisticated type are based on the actually observed distribution of strategies in the experiment's subject pool. A player of this type takes this distribution as a probability distribution for his opponent's choice and plays best reply to this information.

For the estimation of the mixture model let $i=1, \ldots, N$ index the different players, let $k$ $=1, \ldots, K$ index our types, and let $c=2,3$, or 4 be the number of a player's possible decisions in a given game. We assume that a type- $k$ player normally makes type $k$ 's decision,

\footnotetext{
${ }^{14}$ We follow Costa-Gomes et al. (2001) in the selection of types to be considered. As they indicate, the definition of types is largely based on earlier work by Stahl and Wilson $(1994,1995)$. Note that Costa-Gomes et al. (2001) introduce nine types. However, naïve and optimistic types cannot be distinguished in the games used in Costa-Gomes et al. (2001) and here.
} 
but in each game he makes an error with probability $\varepsilon_{k} \in[0,1]$, type $k$ 's error rate, in which case he makes each of his $c$ decisions with probability $1 / c$. For a type- $k$ player, the probability of type $k$ 's decision is then $1-\frac{(c-1)}{c} \varepsilon_{k}$. So the probability of any single non-type $k$ decision is $\frac{\varepsilon_{k}}{c}$. We assume errors are independently and identically distributed across games and players.

The likelihood function can be constructed as follows. Let $T^{c}$ denote the total number of games in which players have $c$ decisions. In our design we have $T^{2}=11, T^{3}=6$, and $T^{4}=1$. Then let $x_{k}^{i c}$ denote the number of player i's decisions that equal type $k$ 's in games in which he has $c$ decisions with $x_{k}^{i}=\left(x_{k}^{i 2}, x_{k}^{i 3}, x_{k}^{i 4}\right), x^{i}=\left(x_{1}^{i}, \ldots, x_{K}^{i}\right)$, and $x=\left(x^{i}, \ldots, x^{N}\right)$. Let $p_{k}$ denote players' common prior $k$-type probability, and $\sum_{k=1}^{K} p_{k}=1$ and $p=\left(p_{1}, \ldots, p_{K}\right)$. Let $\varepsilon_{k}$ denote the $k$-type error rate and $\varepsilon=\left(\varepsilon_{1}, \ldots, \varepsilon_{K}\right)$. Given that a game has one type-k decision and $c-1$ non-type- $k$ decisions, the probability of observing a particular sample with $x_{k}^{i}$ type- $k$ decisions when player $i$ is type $k$ can be written as:

$$
L_{k}^{i}\left(\varepsilon_{k} \mid x_{k}^{i}\right)=\prod_{c=2,3,4}\left[1-\frac{(1-c)}{c} \varepsilon_{k}\right]^{x_{k}^{i c}}\left[\frac{\varepsilon_{k}}{c}\right]^{T^{c}-x_{k}^{i c}}
$$

Weighting the right-hand side by $p_{k}$, summing over $k$, taking logarithms, and summing over $i$ yields the log-likelihood function for the entire sample:

$$
\ln L(p, \varepsilon \mid x)=\sum_{i=1}^{n} \ln \sum_{k=1}^{K} p_{k} L_{k}^{i}\left(\varepsilon_{k} \mid x_{k}^{i}\right)
$$

\section{Table 7 about here}

In Table 7 we provide an estimation of equation (2). We interpret the estimated probability $p_{k}$ as the probability to find a player of type $k$ in the population under observation. The bottom line of Table 7 reveals an estimated share of $41 \%$ of subjects to be a strategic type. Looking at the probability for single types, we note that the non-strategic type optimistic is the modal type with a probability of $40 \%$. Three strategic types are significant and have an estimated probability of roughly 10\%. These are L2 (best replying to optimistic/naïve types), D1 (deleting dominated strategies once and then best reply to a uniform distribution of the 
remaining strategies), and sophisticated (playing best reply to the actually observed frequencies of different strategies).

To measure the effects of gender, age and other individual characteristics on the probability to belong to a given type we use the following procedure. Based on the estimation of (2), we use the estimated parameters $\hat{\varepsilon}_{k}$ and $\hat{p}_{k}$ to compute the probability by which each subject is assigned to a specific type, conditional on the observed pattern of choices. ${ }^{15}$

\section{Table 8 about here}

Table 8 presents Tobit regressions in which we regress the probability of subject $i$ being classified into each of the eight different types on age (years), gender ( $1=$ male), knowledge to play chess, and a subject's grades in math and German language. Including a dummy variable for playing chess was motivated by chess being a highly strategic game where players immediately notice that their success depends not only on own choices, but also on the opponent's choices. While the first eight regressions use as the dependent variable a subject's probability to belong to one of the eight types considered here, the ninth regression considers a subject's probability to be classified as a strategic decision making type as the dependent variable.

We see that age has an impact on the altruistic and D1-type. Older subjects are (weakly significantly) more likely to be altruistic/efficiency-loving, and more likely to apply one round of eliminating dominated strategies (D1-type). There is also a gender effect on these two types, such that boys are more likely of the altruistic/efficiency-loving type, while girls are more likely to be a D1-type. This holds true even when controlling for the other independent variables. Subjects with better math grade - note that lower grades mean better skills in the Austrian system - are more frequently classified as a D1-type. The relatively few equilibriumtypes are largely influenced by good math grades and by playing chess in one's sparetime.

\footnotetext{
${ }^{15}$ For each subject and type, we compute probabilities (1) i.e. the probabilities to observe a given pattern of choices conditional on a type; we denote them by $P\left(x_{i} \mid k=h\right)$, where $h \in\{1, \ldots, 8\}$ and, with abuse of notation, $x_{i}$ denotes the choices of individual $i$. Using Bayes Rule, we compute the probability that an individual $i$ is a type-k, given the observed choices, i.e., $P_{i}\left(k=h \mid x_{i}\right)$ where $h \in\{1, \ldots, 8\}$. For example, the probability that individual $i$ belongs to the Altruistic type $(k=1)$, given the observed choices $x_{i}$, is given by the following equation: $P_{i}\left(k_{i}=1 \mid x_{i}\right)=\frac{P\left(x_{i} \mid k=1\right) \hat{p}_{1}}{P\left(x_{i} \mid k=1\right) \hat{p}_{1}+P\left(x_{i} \mid k=2\right) \hat{p}_{2}+\ldots+P\left(x_{i} \mid k=8\right) \hat{p}_{8}}$.
} 
Overall, the math grade has also an influence on the general likelihood to be a strategic type. However, age or gender has no effect on being a strategic type. This indicates that already 10year olds are equally likely to play these normal-form games strategically as 17-year olds. Only for a specific strategic type, the D1-type, we have found a (weak, though) influence of age.

We can summarize the main results in this subsection as follows:

Result 4: The likelihood of subjects to be of any of five different strategic types (equilibrium, sophisticated, D1, D2, L2) is about 40\%. The modal type, however, is a nonstrategic optimistic type. Age has a positive effect on the probability to be an altruistic/efficiency-loving and a D1-type. The performance in mathematics is correlated with the probability to be one of the strategic types. Age has no impact on the latter probability, though.

\section{Conclusion}

In this paper we have studied strategic sophistication of 191 adolescents, aged 10 to 17 years, in 18 different normal-form games taken from Costa-Gomes et al. (2001). Overall, we have found that about $40 \%$ of subjects can be classified as strategic, thus taking into account their opponent's incentives and strategies when making decisions. Interestingly, we have found no influence of age on the likelihood to be strategic. This result suggests that at the age of 10 years strategic sophistication has already reached a level that - in the aggregate - does not change in the later teenage years. In fact, many of the stylized facts found in our experiment with teenagers are very similar to what is known from experiments with university students in their early 20ies. The relative frequency of playing Nash in the 18 different games is approximately $45 \%$ in our subject pool, which is well in the range of $40 \%$ to $50 \%$ of Nash-play reported in other studies (e.g., Costa-Gomes et al., 2001; Costa-Gomes and Weizsäcker, 2008; Fehr et al., 2008; Sutter et al., 2010a). The share of consistent decisions - as best response to one's own beliefs - is around $60 \%$ in our sample, while it is around 55\% both in Costa-Gomes and Weizsäcker (2008) and Sutter et al. (2010a) who have run their experiments with university students. Hence, our first main finding is that teenagers and young adults in their early 20ies play normal form games in a very similar manner. In fact, we have only found a few noteworthy effects of age, in particular on the likelihood to be 
altruistic/efficiency-loving and a D1-type. Both get (weakly significantly) more likely with age. Analytic skills, captured in subjects' math grades, have a positive influence on being a strategic type in general, and a D1- or equilibrium-type in particular. Hence, experimental behavior in normal-form games is related to math skills. While the previous literature on strategic sophistication has not put much emphasis on gender effects, we have found a few results. Girls are more likely to be a D1-type, while boys are more likely to be altruistic/efficiency-loving. ${ }^{16}$ In the aggregate, however, we have found no gender differences in the likelihood to be strategic.

While our paper has contributed to the literature on strategic sophistication by showing that adolescents are able to play complex games in a way that is very similar to the behavior of adults (university students) and that age has no marked impact in strategic behavior, another contribution to this literature refers to the analysis of Nash-consistency. We have defined this term as playing Nash and expecting the opponent to do so as well. This analysis touches on the foundations of standard game-theoretic reasoning, thereby contributing to a better understanding of bounded rationality. Our analysis (in section 3.3) has shown that dominant strategies (of the player himself or of the opponent) make Nash-consistency more likely. However, we have also found out that this type of consistency depends on the possible losses from playing Nash and - as far as the opponent's expected Nash-consistency is concerned - on distributional preferences. As payoffs in equilibrium become more unequal, consistency between first- and second-order beliefs becomes less likely. Hence, the distribution of actual payoffs and the potential alternative payoffs play an important role in determining the strategic sophistication of players. We consider this an important finding as it documents an interaction of strategic sophistication and distributional preferences.

Given our results on the stability of behavior in our sample of 10- to 17-year olds, one straightforward extension of our study would be studying also subjects who are younger than 10 years of age in order to determine whether and when noticeable changes in the ability to act and think strategically develop. Our experimental design is most likely not the optimal choice for younger children below the age of 10 years, because the games used in our study and the decisions on first- and second-order beliefs might easily overburden younger children. While we have chosen our design due to its suitability for studying different types of strategic and non-strategic behavior and because a lot of evidence from college or university students in their early 20ies is available for comparison, we regard it as an interesting avenue for future

\footnotetext{
${ }^{16}$ The latter finding resonates in simple distribution experiments where boys are more often found to care for efficiency than girls. See Sutter et al. (2010b).
} 
research to design simpler games that could provide insights into how strategic sophistication, and the interaction of choices and beliefs, develops in the first ten years of human life. 


\section{References}

Bhatt, M., Camerer, C. F. (2005), Self-referential thinking and equilibrium as states of mind in games: fMRI evidence. Games and Economic Behavior 52: 424-459.

Camerer, C. F. (2003), Behavioral Game Theory. Experiments in Strategic Interaction. Princeton, Princeton University Press.

Costa-Gomes, M., Crawford, V. (2006), Cognition and behavior in guessing games: An experimental study. American Economic Review 96: 1737-1768.

Costa-Gomes, M., Crawford, V., Broseta, B. (2001), Cognition and behavior in normal-form games: An experimental study. Econometrica 69: 1193-1235.

Costa-Gomes, M., Weizsäcker, G. (2008), Stated beliefs and play in normal-form games. The Review of Economic Studies 75: 729-762.

Crawford, V., Iriberri, N. (2007), Fatal attraction: Salience, naiveté, and sophistication in experimental “Hide-and-Seek” games. American Economic Review 97: 1731-1750.

Fehr, D., Kübler, D., Danz, D. (2008), Information and beliefs in a repeated normal-form game. Working Paper, Technical University of Berlin.

Fehr, E., Schmidt, K. (1999), A theory of fairness, competition, and cooperation. Quarterly Journal of Economics 114: 817-868.

Goeree, J., Holt, C. (2004), A model of noisy introspection. Games and Economic Behavior 46: 365-382.

Harbaugh, W. T., Krause, K. (2000), Children's altruism in public good and dictator experiments. Economic Inquiry 38: 95-109.

Harbaugh, W. T., Krause, K., Liday, S. G. Jr. (2003a), Children's bargaining behavior. Working Paper, University of Oregon.

Harbaugh, W. T., Krause, K., Liday, S. G. Jr., Vesterlund, L. (2003b), Trust in children. in: Ostrom, E., Walker, J. (Eds.), Trust, Reciprocity and Gains from Association: Interdisciplinary Lessons from Experimental Research. New York City. Russell Sage Foundation.

Haruvy, E. (2002), Identification and testing of modes in beliefs. Journal of Mathematical Psychology 46: 88-109.

Haruvy, E., Stahl, D., Wilson, P. (1999), Evidence for optimistic and pessimistic behavior in normal-form games. Economic Letters 63: 255-259.

Murnighan, J.K., Saxon, M.S. (1998), Ultimatum bargaining by children and adults. Journal of Economic Psychology 19: 415-445. 
Rey-Biel, P. (2009), Equilibrium play and best response to (stated) beliefs in normal form games. Games and Economic Behavior 65: 572-585.

Stahl, D., Wilson, P. (1994), Experimental evidence of players' models of other players. Journal of Economic Behavior and Organziation 25: 309-327.

Stahl, D., Wilson, P. (1995), On players' models of other players: theory and experimental evidence. Games and Economic Behavior 10: 213-254.

Sutter, M. (2007), Outcomes versus intentions: On the nature of fair behavior and its development with age. Journal of Economic Psychology 28: 69-78.

Sutter, M., Czermak, S., Feri, F. (2010a), Strategic sophistication of individuals and teams in experimental normal-form games. IZA Discussion Paper 4732.

Sutter, M., Feri, F., Kocher, M., Martinsson, P., Nordblom, K., Ruetzler, D. (2010b), Social preferences in childhood and adolescence - A large-scale experiment. University of Innsbruck. IZA Discussion Paper 5016.

Sutter, M., Kocher, M. (2007), Trust and trustworthiness across different age groups. Games and Economic Behavior 59: 364-382.

Weizsäcker, G. (2003), Ignoring the rationality of others: evidence from experimental normalform games. Games and Economic Behavior 44: 145-171. 


\section{Tables and Figures}

Table 1: Choices and beliefs (relative frequencies in \%)

\begin{tabular}{lccc}
\hline \hline & All games & D-games & ND-games \\
& \multicolumn{4}{c}{ CHOICES } \\
Nash & 45.31 & 62.31 & 24.08 \\
Pareto & 46.63 & 34.71 & 61.52 \\
Other & 8.06 & 2.99 & 14.40 \\
\hline \multicolumn{4}{c}{ FIRST-ORDER BELIEFS } \\
Nash & 34.20 & 50.99 \\
Pareto & 57.88 & 46.28 & 13.22 \\
Other & 7.91 & 2.72 & 72.39 \\
\hline \multicolumn{4}{c}{ SECOND-ORDER BELIEFS } \\
Nash & 34.64 & 49.84 & 14.40 \\
Pareto & 57.10 & 47.38 & 15.64 \\
Other & 8.26 & 2.77 & 69.24 \\
\hline \hline
\end{tabular}


Table 2: Complexity of the game, choices and beliefs (relative frequencies in \%)

\begin{tabular}{|c|c|c|c|c|c|}
\hline $\begin{array}{l}\text { Complexity } \\
\text { (game type) }^{\mathrm{a}}\end{array}$ & $1 R(D)$ & $2 R(D)$ & $2 R(N D)$ & $3 R(N D)$ & $\infty R(N D)$ \\
\hline \multicolumn{6}{|c|}{ CHOICES } \\
\hline Nash & 85.34 & 39.27 & 35.08 & 8.11 & 26.57 \\
\hline Pareto & 12.14 & 57.28 & 64.92 & 47.91 & 66.62 \\
\hline Other & 2.51 & 3.46 & 0.00 & 43.98 & 6.81 \\
\hline \multicolumn{6}{|c|}{ FIRST-ORDER BELIEFS } \\
\hline Nash & 87.02 & 14.98 & 14.39 & 9.42 & 14.53 \\
\hline Pareto & 10.78 & 81.78 & 85.61 & 48.17 & 77.88 \\
\hline Other & 2.20 & 3.25 & 0.00 & 42.41 & 7.59 \\
\hline \multicolumn{6}{|c|}{ SECOND-ORDER BELIEFS } \\
\hline Nash & 80.84 & 18.85 & 13.61 & 11.78 & 18.59 \\
\hline Pareto & 16.54 & 78.22 & 86.39 & 46.60 & 71.99 \\
\hline Other & 2.62 & 2.93 & 0.00 & 41.62 & 9.42 \\
\hline
\end{tabular}

" ${ }^{a}$ The columns separate behavior according to (i) the different number of rounds (R) of iterated purestrategy dominance a player needs to identify the own equilibrium choice, and (ii) the presence (D) or absence (ND) of a dominant strategy in the game. 
Table 3: Consistency of decisions (relative frequency of best reply)

\begin{tabular}{llll}
\hline \hline & All games & D-games & ND-games \\
\cline { 2 - 4 } $\begin{array}{l}\text { Own consistency } \\
\begin{array}{l}\text { Choice is best reply to first- } \\
\text { order belief }\end{array}\end{array}$ & 62.84 & 66.15 & 58.71 \\
\cline { 2 - 3 } & & \\
$\begin{array}{l}\text { Opponent's expected } \\
\text { consistency }\end{array}$ & 52.75 & 56.17 & 48.49 \\
$\begin{array}{l}\text { First-order belief is best } \\
\text { reply to second-order belief }\end{array}$ & & \\
\hline \hline
\end{tabular}


Table 4: Relative frequency of consistency-types Nash-CON and Max-CON

\begin{tabular}{llccc}
\hline \hline & & All games & D-games & ND-games \\
\cline { 3 - 5 } $\begin{array}{l}\text { Player's } \\
\text { own } \\
\text { consistency }\end{array}$ & Nash-CON & 16.04 & 24.47 & 5.50 \\
$\begin{array}{l}\text { Expected } \\
\begin{array}{l}\text { consistency } \\
\text { of opponent }\end{array}\end{array}$ & Nash-CON & 39.13 & 39.43 & 38.74 \\
\hline \hline
\end{tabular}


Table 5: Determinants of a player's consistency-type Nash-CON

\begin{tabular}{lccc}
\hline Variable & Coefficient & Std. error & p-value \\
& & & \\
\hline dominant strategy & 1.079 & 0.163 & 0.000 \\
opponent dominant strategy & 1.231 & 0.112 & 0.000 \\
dummy for $\mathbf{7}^{\text {th }}$ grade & -0.053 & 0.129 & 0.684 \\
dummy for $\mathbf{9}^{\text {th }}$ grade & 0.130 & 0.139 & 0.349 \\
dummy for $\mathbf{1 1}^{\text {th }}$ grade & -0.009 & 0.132 & 0.948 \\
risk with maxstrategy & 0.017 & 0.005 & 0.000 \\
inequality in Nash (player's advantage) & -0.006 & 0.009 & 0.528 \\
inequality in Nash (players's disadvantage) & -0.014 & 0.010 & 0.172 \\
Constant & -1.981 & 0.246 & 0.000 \\
\hline$N=3.438$; standard errors clustered for the 191 decision makers $\left(45\right.$ in $5^{\text {th }}$ grade, 52 in $7^{\text {th }}$ grade, \\
52 in $9^{\text {th }}$ grade, 42 in $11^{\text {th }}$ grade).
\end{tabular}

Marginal effects of independent variables

\begin{tabular}{lccr}
\hline \hline & Marginal effect & Std. error & p-value \\
\hline dominant strategy & 0.283 & 0.051 & 0.000 \\
opponent dominant strategy & 0.331 & 0.034 & 0.000 \\
dummy for $\mathbf{7}^{\text {th }}$ grade & -0.011 & 0.026 & 0.684 \\
dummy for $\mathbf{9}^{\text {th }}$ grade & 0.028 & 0.031 & 0.349 \\
dummy for $\mathbf{1 1}{ }^{\text {th }}$ grade & -0.002 & 0.027 & 0.948 \\
risk with maxstrategy & 0.004 & 0.001 & 0.000 \\
inequality in Nash (player's advantage) & -0.001 & 0.002 & 0.528 \\
inequality in Nash (players's disadvantage) & 0.003 & 0.002 & 0.172 \\
\hline \hline
\end{tabular}

N = 3.438; standard errors clustered for the 191 decision makers ( 45 in $5^{\text {th }}$ grade, 52 in $7^{\text {th }}$ grade,

52 in $9^{\text {th }}$ grade, 42 in $11^{\text {th }}$ grade). 
Table 6: Determinants of the opponent's expected consistency-type Nash-CON

\begin{tabular}{lccc}
\hline \hline Variable & Coefficient & Std. error & p-value \\
\hline dominant strategy & 1.272 & 0.193 & 0.000 \\
opponent dominant strategy & 0.710 & 0.122 & 0.000 \\
dummy for $\mathbf{7}^{\text {th }}$ grade & -0.274 & 0.135 & 0.042 \\
dummy for $\mathbf{9}^{\text {th }}$ grade & 0.057 & 0.125 & 0.648 \\
dummy for $\mathbf{1 1}^{\text {th }}$ grade & -0.072 & 0.125 & 0.564 \\
risk with maxstrategy & 0.015 & 0.006 & 0.008 \\
inequality in Nash (player's advantage) & -0.022 & 0.011 & 0.046 \\
inequality in Nash (players's disadvantage) & -0.018 & 0.012 & 0.145 \\
Constant & -1.853 & 0.291 & 0.000 \\
\hline \hline$N=3.438 ;$ standard errors clustered for the 191 decision makers $\left(45\right.$ in $5^{\text {th }}$ grade, 52 in $7^{\text {th }}$ grade, \\
52 in $9^{\text {th }}$ grade, 42 in $11^{\text {th }}$ grade). & &
\end{tabular}

Marginal effects of independent variables

\begin{tabular}{lccr}
\hline \hline & Marginal effect & Std. error & p-value \\
\hline dominant strategy & 0.266 & 0.053 & 0.000 \\
opponent dominant strategy & 0.127 & 0.026 & 0.000 \\
dummy for $\mathbf{7}^{\text {th }}$ grade & -0.036 & 0.016 & 0.042 \\
dummy for $\mathbf{9}^{\text {th }}$ grade & 0.008 & 0.019 & 0.648 \\
dummy for $\mathbf{1 1}^{\text {th }}$ grade & -0.010 & 0.017 & 0.564 \\
risk with maxstrategy & 0.002 & 0.001 & 0.008 \\
inequality in Nash (player's advantage) & -0.003 & 0.002 & 0.046 \\
inequality in Nash (players's disadvantage) & -0.003 & 0.002 & 0.145 \\
\hline \hline$N=3.438 ;$ standard errors clustered for the 191 decision makers (45 in $5^{\text {th }}$ grade, 52 in $7^{\text {th }}$ grade, \\
52 in $9^{\text {th }}$ grade, 42 in $11^{\text {th }}$ grade). & &
\end{tabular}


Table 7: Estimated probability $p_{k}$ of types - Own choices

\begin{tabular}{ll}
\hline \hline Age group & \\
\hline Altruistic / Efficiency-loving & $0.039^{* * *}$ \\
Pessimistic & $0.146^{* * *}$ \\
Optimistic & $0.404^{* * *}$ \\
L2 & $0.138^{* * *}$ \\
D1 & $0.107^{* * *}$ \\
D2 & 0.040 \\
Equilibrium & 0.026 \\
Sophisticated & $0.100^{* *}$ \\
\hline Sum Strategic types & $0.410^{* * *}$ \\
\hline *** (**) [*] significant at 1\% (5\%) [10\%] level
\end{tabular}


Table 8: Tobit regressions

\begin{tabular}{|c|c|c|c|c|}
\hline & & Coefficient & Std. Error & p-value \\
\hline \multirow[t]{6}{*}{ Alturistic } & gender (1=male) & 0.051 & 0.029 & 0.081 \\
\hline & age (in years) & 0.014 & 0.007 & 0.069 \\
\hline & chess & 0.041 & 0.031 & 0.185 \\
\hline & mathgrade & -0.004 & 0.017 & 0.837 \\
\hline & germangrade & 0.002 & 0.020 & 0.931 \\
\hline & constant & -0.183 & 0.091 & 0.045 \\
\hline \multirow[t]{6}{*}{ Pessimistic } & gender (1=male) & -0.032 & 0.043 & 0.458 \\
\hline & age (in years) & -0.004 & 0.011 & 0.688 \\
\hline & chess & 0.027 & 0.045 & 0.559 \\
\hline & mathgrade & 0.014 & 0.025 & 0.569 \\
\hline & germangrade & 0.001 & 0.029 & 0.985 \\
\hline & constant & 0.162 & 0.133 & 0.224 \\
\hline \multirow[t]{6}{*}{ Optimistic } & gender (1=male) & -0.004 & 0.072 & 0.952 \\
\hline & age (in years) & -0.021 & 0.018 & 0.254 \\
\hline & chess & -0.001 & 0.077 & 0.988 \\
\hline & mathgrade & 0.067 & 0.043 & 0.117 \\
\hline & germangrade & -0.036 & 0.050 & 0.473 \\
\hline & constant & 0.603 & 0.225 & 0.008 \\
\hline \multirow[t]{6}{*}{ L2-type } & gender (1=male) & 0.011 & 0.050 & 0.823 \\
\hline & age (in years) & -0.007 & 0.013 & 0.569 \\
\hline & chess & -0.064 & 0.053 & 0.225 \\
\hline & mathgrade & 0.005 & 0.029 & 0.864 \\
\hline & germangrade & -0.048 & 0.034 & 0.164 \\
\hline & constant & 0.370 & 0.154 & 0.017 \\
\hline \multirow[t]{6}{*}{ D1-type } & gender ( $1=$ male $)$ & -0.070 & 0.035 & 0.050 \\
\hline & age (in years) & 0.016 & 0.009 & 0.071 \\
\hline & chess & -0.030 & 0.038 & 0.433 \\
\hline & mathgrade & -0.049 & 0.021 & 0.019 \\
\hline & germangrade & 0.048 & 0.024 & 0.048 \\
\hline & constant & -0.038 & 0.110 & 0.731 \\
\hline \multirow[t]{6}{*}{ D2-type } & gender $(1=$ male $)$ & 0.010 & 0.013 & 0.470 \\
\hline & age (in years) & 0.001 & 0.003 & 0.808 \\
\hline & chess & -0.008 & 0.014 & 0.562 \\
\hline & mathgrade & 0.005 & 0.008 & 0.506 \\
\hline & germangrade & -0.005 & 0.009 & 0.539 \\
\hline & constant & 0.017 & 0.042 & 0.683 \\
\hline \multirow[t]{6}{*}{ Equilibrium } & gender ( $1=$ male $)$ & 0.022 & 0.021 & 0.301 \\
\hline & age (in years) & 0.002 & 0.005 & 0.755 \\
\hline & chess & 0.041 & 0.023 & 0.075 \\
\hline & mathgrade & -0.025 & 0.013 & 0.049 \\
\hline & germangrade & 0.014 & 0.015 & 0.332 \\
\hline & constant & -0.006 & 0.066 & 0.923 \\
\hline \multirow[t]{6}{*}{ Sophisticated } & gender (1=male) & 0.012 & 0.031 & 0.704 \\
\hline & age (in years) & 0.000 & 0.008 & 0.988 \\
\hline & chess & -0.005 & 0.032 & 0.866 \\
\hline & mathgrade & -0.014 & 0.018 & 0.437 \\
\hline & germangrade & 0.024 & 0.021 & 0.255 \\
\hline & constant & 0.075 & 0.095 & 0.433 \\
\hline Sum & gender (1=male) & -0.015 & 0.070 & 0.828 \\
\hline \multirow[t]{5}{*}{ Strategic types } & age (in years) & 0.012 & 0.018 & 0.511 \\
\hline & chess & -0.067 & 0.075 & 0.373 \\
\hline & mathgrade & -0.078 & 0.042 & 0.062 \\
\hline & germangrade & 0.033 & 0.048 & 0.490 \\
\hline & constant & 0.418 & 0.219 & 0.058 \\
\hline
\end{tabular}


Figure 1. The 18 normal-form games

\begin{tabular}{ccc}
\multicolumn{2}{c}{ game \# $\mathbf{3}(\boldsymbol{D})$} & [1R, 2R] \\
\hline & 1 & 2 \\
\hline 1 & 72,93 & 31,46 \\
2 & 84,52 & 55,79 \\
\hline \hline & \\
game \# 1 (D) & [2R, 1R] \\
\hline \hline & 1 & 2 \\
\hline 1 & 75,51 & 42,27 \\
2 & 48,80 & 89,68 \\
\hline \hline
\end{tabular}

\begin{tabular}{|c|c|}
\hline 1 & 2 \\
\hline 94,23 & 38,57 \\
\hline 45,89 & 14,18 \\
\hline
\end{tabular}

\begin{tabular}{|c|c|c|}
\hline 1 & 2 & 3 \\
\hline 59,58 & 46,83 & 85,61 \\
\hline 38,29 & 70,52 & 37,23 \\
\hline
\end{tabular}

\begin{tabular}{|c|c|}
\hline game \# $12(D)$ & {$[2 \mathrm{R}, 1 \mathrm{R}]$} \\
\hline 1 & 2 \\
\hline 21,92 & 87,43 \\
\hline 55,36 & 16,12 \\
\hline
\end{tabular}

\begin{tabular}{ccc} 
& game \# 11 (D) & [2R, 1R] \\
\hline \hline 1 & 2 \\
\hline 31,32 & 68,46 \\
2 & 72,43 & 47,61 \\
3 & 91,65 & 43,84 \\
\hline \hline
\end{tabular}

\begin{tabular}{ccc} 
& game \# $\mathbf{9}(\boldsymbol{D})$ & $\mathbf{[ 1 R}, \mathbf{2 R}]$ \\
\hline \hline 1 & 2 \\
\hline 1 & 28,37 & 57,58 \\
2 & 22,36 & 60,84 \\
3 & 51,69 & 82,45 \\
\hline \hline
\end{tabular}

\begin{tabular}{|c|c|c|}
\hline ne \# & ? & {$[1 \mathrm{R}, 2 \mathrm{R}$} \\
\hline$\frac{1}{42,64}$ & $\frac{2}{57.43}$ & $\frac{3}{80.39}$ \\
\hline 28,27 & 39,68 & 61,87 \\
\hline
\end{tabular}

\begin{tabular}{ccc} 
& game \# $\mathbf{6}(\mathbf{N D})$ & [3R, 2R] \\
\hline \hline 1 & 1 \\
\hline 1 & 53,86 & 24,19 \\
2 & 79,57 & 42,73 \\
3 & 28,23 & 71,50 \\
\hline \hline
\end{tabular}

\begin{tabular}{|c|c|c|}
\hline 1 & 2 & 3 \\
\hline 21,26 & 52,73 & 75,44 \\
\hline 88,55 & 25,30 & 59,81 \\
\hline
\end{tabular}

\begin{tabular}{ccc} 
game \# 15 (ND) & [3R, 2R] \\
\hline \hline 1 & 2 \\
\hline 7 & 76,93 & 25,12 \\
2 & 43,40 & 74,62 \\
3 & 94,16 & 59,37 \\
\hline \hline
\end{tabular}

\begin{tabular}{|c|c|c|}
\hline 1 & 2 & 3 \\
\hline 42,45 & 95,78 & 18,96 \\
\hline 64,76 & 14,27 & 39,61 \\
\hline
\end{tabular}

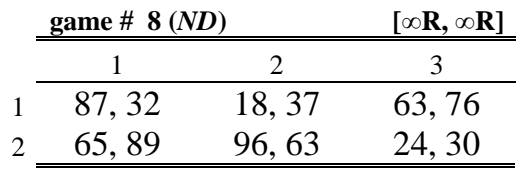

\begin{tabular}{|c|c|c|}
\hline 1 & 2 & 3 \\
\hline 67,91 & 95,64 & 31,35 \\
\hline 89,49 & 23,53 & 56,78 \\
\hline
\end{tabular}

\begin{tabular}{ccc} 
& game \# $\mathbf{5}(\boldsymbol{N D})$ & {$[\infty \mathbf{R}, \infty \mathbf{R}]$} \\
\hline & 1 & 2 \\
\hline 1 & 72,59 & 26,20 \\
2 & 33,14 & 59,92 \\
3 & 28,83 & 85,61 \\
\hline \hline
\end{tabular}

\begin{tabular}{|c|c|}
\hline game \# 4 (ND) & {$[\infty \mathbf{R}, \infty \mathbf{R}]$} \\
\hline 1 & 2 \\
\hline 46,16 & 57,88 \\
\hline 71,49 & 28,24 \\
\hline 42,82 & 84,60 \\
\hline
\end{tabular}

\begin{tabular}{ccc} 
& game \# $\mathbf{~ 1 7}(\boldsymbol{D})$ & $\mathbf{[ 1 R , ~ 2 R ]}$ \\
\hline 1 & 2 \\
\hline 1 & 22,14 & 57,55 \\
2 & 30,42 & 28,37 \\
3 & 15,60 & 61,88 \\
4 & 45,66 & 82,31 \\
\hline \hline
\end{tabular}






\section{Supplementary material}

\section{A. Experimental instructions}

Instructions were read aloud at the beginning of each session. Before the experiment started, all participants had to answer control questions in order to make sure that they understood the instructions. Instructions primarily served as a basic guideline for a very detailed explanation of the game. As we wanted to be sure that our participants understood the rules of the game we took a lot of effort to explain them the instructions in a very detailed way and if necessary even personally. Originally all instructions were in German. In the following we present an English translation of the instructions and control questions used.

Instructions for $5^{\text {th }}$ and $7^{\text {th }}$ graders differ from instructions for $9^{\text {th }}$ and $11^{\text {th }}$ graders with respect to payoffs. In the following we present instructions for $5^{\text {th }}$ and $7^{\text {th }}$ graders as a baseline and indicate payoffs which were used for $9^{\text {th }}$ and $11^{\text {th }}$ graders in brackets and underlined letters.

Welcome! In this game it is very important that you do not communicate with any of your class mates for the whole duration of the game. Students who break this rule will be excluded from the game. You will earn some money by playing this game which will be paid to you at the end of the game. The amount of money you earn strongly depends on your decisions during the game. Thus it is very important that you understand the rules of the game. Please read the instructions carefully. As soon as you have any questions, please raise your hand and an instructor of the game will come to you in order to answer your questions.

Today we will play a game consisting of 18 sub-games. Each sub-game is printed on a separate sheet of paper and consists of three decisions each player needs to make. The rules for those three decisions will be explained to you soon. Each player gets 18 sheets on which he needs to make his decisions.

You will play in groups of two students. Each student of this room will be matched with a student from another room. In this other room students from your parallel-class play the same game right now. The student with the number one in this room will be matched with student number one in the other room, student number two in this room will be matched with student number two in the other room etc. Same as you did, students in the other room have drawn numbers randomly. We take care that each student in this room is paired with a student in the other room. In the following we will call the student who is matched with you as "the other player" or "your interaction partner”.

We would like to explain the rules of the game based on the following examples: 


\section{Example for decision 1:}

\section{Which row do you want to choose?}
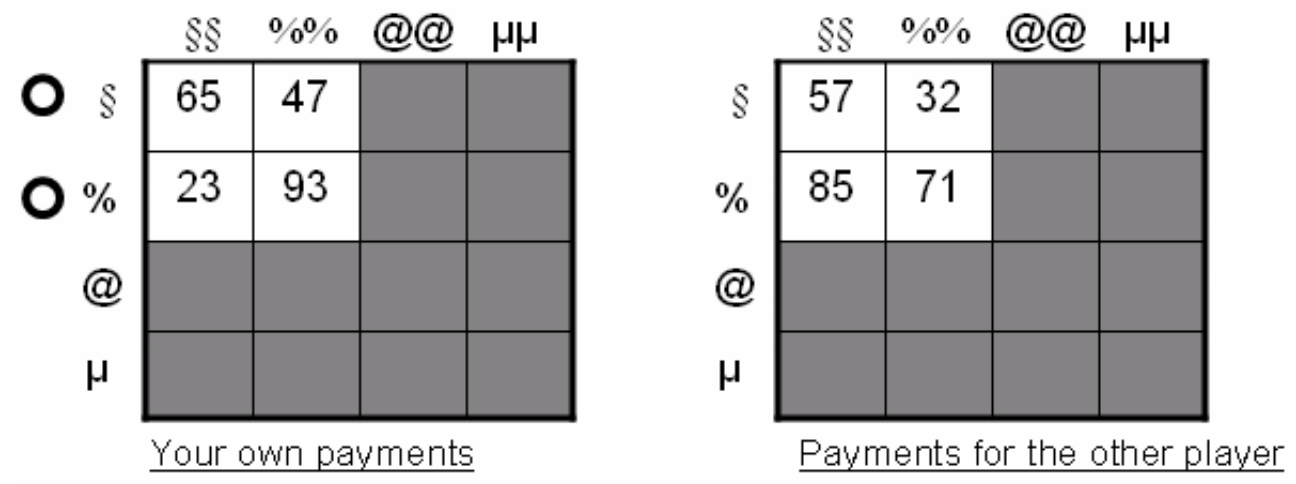

In the upper part of each sheet you need to make a decision. In this example you need to choose one of two options. The first option (first row) is indicated with the sign $\S$ and the second option (second row) is indicated with the sign \%. Your interaction partner also has two options in this example. His options are columns which are always indicated with two signs of the same kind. The first option of the other player is indicated with $\S \S$ and the second option is indicated with \%\%.

Based on the row that you have chosen and the column that your interaction partner has chosen the potential payment for both players is determined. This is done as follows: The table on the left hand side contains four possible payments dedicated to you and measured in game points. The table on the right hand side contains four possible payments dedicated for the opponent player - again measured in game points. The cell that is relevant for payment is dependent on your own decision and on the decision of your interaction partner.

Let's assume you choose the row indicated with the sign $\S$ and your interaction partner chooses the column indicated with the signs $\S \S$. In this particular case you would get 65 points and your interaction partner would get 57 points. Let's assume another case in which you choose the row indicated with the sign \% and the other player chooses the column indicated with the signs $\S \S$. In this case you would get 23 points and your interaction partner would get 85 points.

You can make your choice by marking the circle next to the sign you want to pick with a cross. 


\section{Example for decision 2:}

Which column does your interaction partner choose according to your opinion?
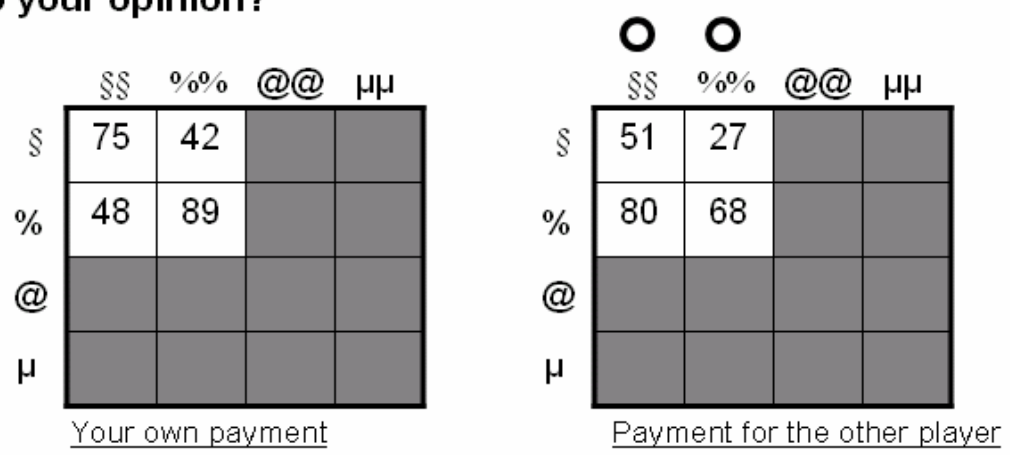

In the middle of each sheet we ask you for your opinion about your interaction partner's choice.

For example if you would belief that your interaction partner chooses the column indicated by the signs $\S \S$ you need to mark the circle above those signs with a cross. If you think that your interaction partner chooses the column marked with the signs \%\% you need to mark the circle above the signs $\% \%$ with a cross. Please note that correct beliefs can result in considerable higher payments.

\section{Example for decision 3:}

Which row does your interaction partner pick when he informs about his belief regarding your own choice?
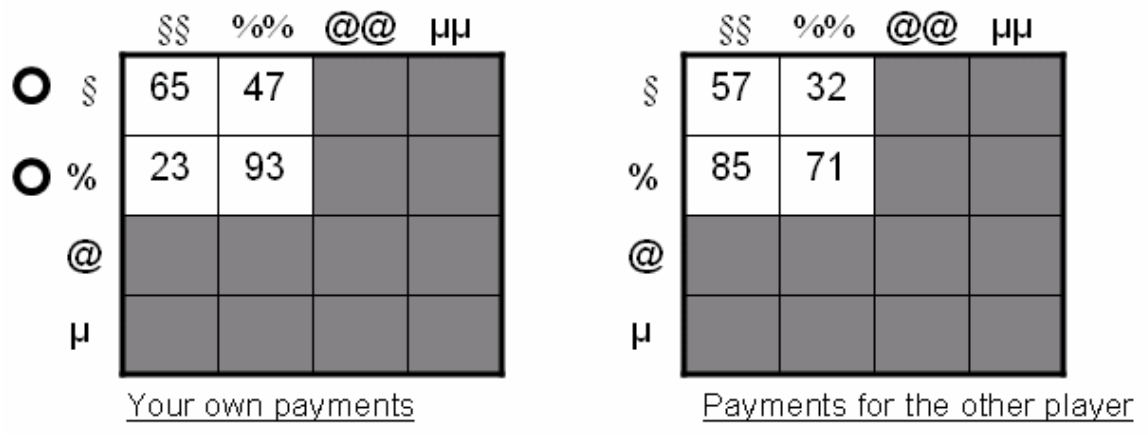

In the lower part of each sheet we ask you for your opinion about your interaction partner's belief regarding your own choice.

For example if you belief that your interaction partner expects you to choose the row indicated with the sign $\S$ you need to mark the circle next to the sign $\S$ with a cross. If you think that your interaction partner expects you to choose the row indicated with the sign \% you need to mark the circle next to the sign \% with a cross. Please note that correct beliefs can result in considerable higher payments.

In the example illustrated above each player has two options from which he can choose. In general there are also games in which one of the two players has not only two, but three or four options from which he can choose. 


\section{Calculation of payments:}

At the end of the whole experiment we will randomly select a sheet which is relevant for payment. We have a deck of cards showing the numbers 1 to 18 from which you or the other player will be allowed to draw one card. The number shown on this card determines the sheet which is relevant for payment.

In addition you will select one decision which will be basis for your payment.

Your decisions are:

- which row is your own choice

- which column chooses your interaction partner according to your opinion

- which row does your interaction partner pick when he informs about his belief regarding your own choice

The selection of the decision that is going to be relevant for payment will be random. You or your interaction partner will draw a card from a deck of three cards showing the numbers 1-3.

\section{Payment for decision 1:}

In the case that the card showing the number 1 is drawn, you and your interaction partner get paid for the first decision. Each point will be converted into Euro according to the following exchange rate

$$
1 \text { point }=0.10 \text { Euros }(0.20 \text { Euros })
$$

Let's assume you have chosen $\S$ and your interaction partner has chosen \%\%. In the example illustrated before this would mean that you earn 4.7 Euros $\underline{(9.4 \text { Euros })}(0.1 * 47$ points $)(0.2 *$ $\underline{47 \text { points })}$ while your interaction partner earns 3.2 Euros $\underline{(6.4 \text { Euros })}(0.1 * 32$ points) $\underline{(0.2 *}$ $\underline{32 \text { points). }}$.

\section{Payment for decision 2:}

In the case that the card showing the number 2 is drawn, you and your interaction partner get paid for the second decision. In this case you will get 5 Euros (10 Euros) if your prediction of your interaction partner's choice was correct. If your prediction was incorrect you will get no payment in this case.

\section{Payment for decision 3:}

In the case that the card showing the number 3 is drawn, you and your interaction partner get paid for the third decision. In this case you get 5 Euros (10 Euros) if your prediction of your interaction partner's expectation (regarding your own choice) was correct. If your prediction was incorrect you will get no payment in this case.

In addition to the payments described in the former each participant of the game gets a fixed amount of 2 Euros (4 Euros) for attending the game. 


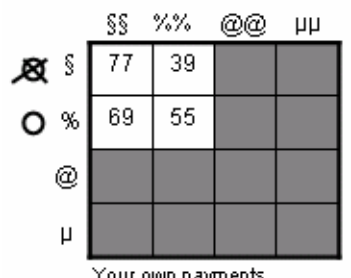

Your omin pauments

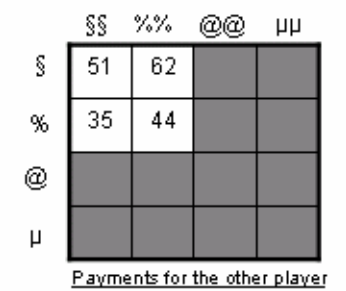

Which column does your interaction partner choose according to your opinion?

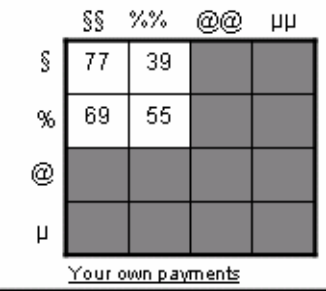

○

$\S \S \% \% \quad @ @ \quad \mu \mu$

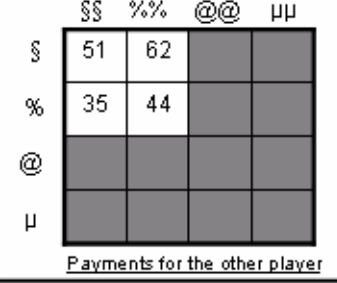

Which row does your interaction partner pick when he informs about his belief regarding your own choice?
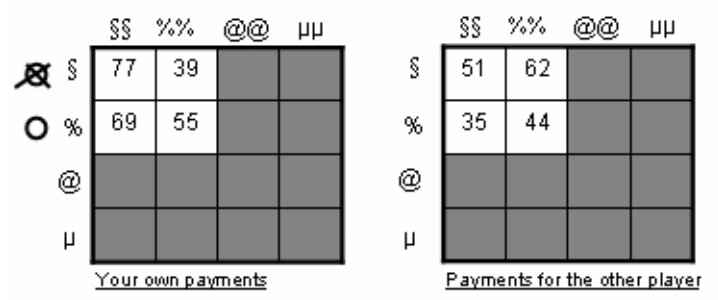

\section{Control-questions:}

1) Assume you and your interaction partner get paid for decision 1.

a) what is your payment in points / Euro in the case your interaction partner has chosen $\S \S$ ?

points

b) what is your interaction partners payment in points Euro, in the case he has chosen $\% \%$ ?

points

c) what is your payment in points / Euro in the case your interaction partner has chosen $\% \%$ ?

$$
\text { points }
$$

2) Assume you and your interaction partner get paid for decision 2.

a) what is your payment in the case your interaction partner has chosen $\S \S$ when he took decision 1 ?

$$
\text { Euro }
$$

3) Assume you and your interaction partner get paid for decision 3 .

a) what is your payment in the case your interaction partner has chosen $\S$ when he took decision 2 ? Euro
Which row do you want to choose?
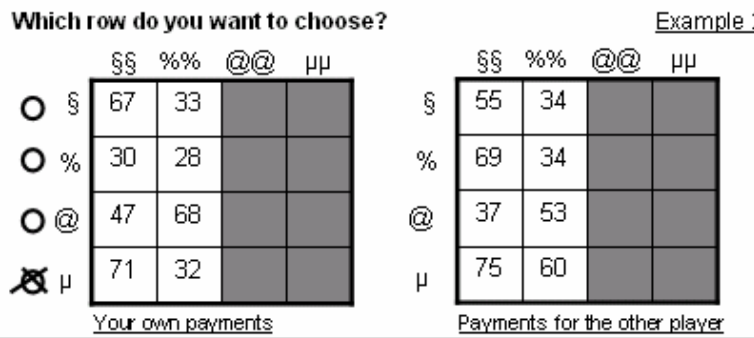

Which column does your interaction partner choose according to your op inion?

\section{\& 0}

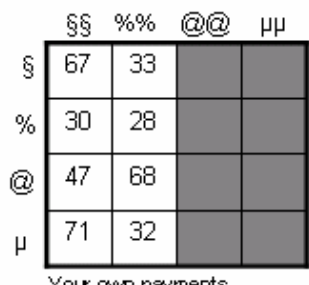

$\S \S \% \% @ \quad \mu$

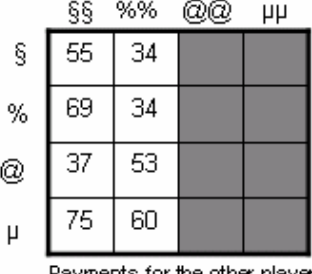

Pavments for the other plaver

Which row does your interaction partner pick when he informs about his belief regarding your own choice?
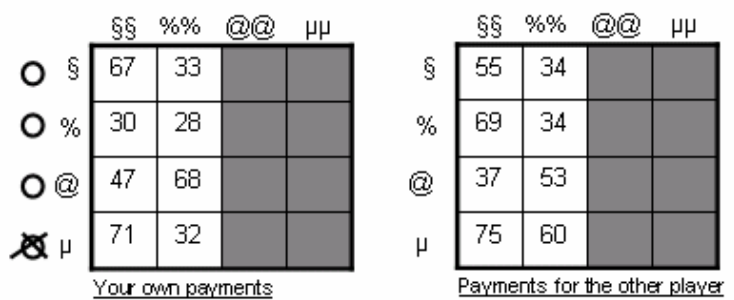

Participant ID:

Class ID:

\section{Control-questions:}

1) Assume you and your interaction partner get paid for decision 1

a) what is your payment in points / Euro in the case your interaction partner has chosen $\S \S$ ?

$$
\text { points }
$$

b) what is your interaction partners payment in points / Euro, in the case he has chosen $\S \S$ ?

$$
\text { points }
$$

c) what is your payment in points / Euro in the case your interaction partner has chosen $\% \%$ ?

points

2) Assume you and your interaction partner get paid for decision 2

a) what is your payment in the case your interaction partner has chosen $\S \S$ when he took decision 1 ?

$$
\text { Euro }
$$

3) Assume you and your interaction partner get paid for decision 3 .

a) what is your payment in the case your interaction partner has chosen @ when he took decision 2?

Euro 


\section{B. Disaggregate data for the four different grades}

Table S1: Choices and beliefs of adolescents (relative frequencies in \%)

\begin{tabular}{|c|c|c|c|}
\hline & All games & D-games & ND-games \\
\hline \multicolumn{4}{|c|}{ CHOICES } \\
\hline Nash $5^{\text {th }}$ grade & 47.90 & 64.67 & 26.94 \\
\hline Nash $7^{\text {th }}$ grade & 45.62 & 62.12 & 25.00 \\
\hline Nash $9^{\text {th }}$ grade & 45.83 & 63.08 & 24.28 \\
\hline Nash $11^{\text {th }}$ grade & 41.53 & 59.05 & 19.64 \\
\hline Pareto $5^{\text {th }}$ grade & 43.58 & 31.56 & 58.61 \\
\hline Pareto $7^{\text {th }}$ grade & 46.80 & 35.38 & 61.06 \\
\hline Pareto $9^{\text {th }}$ grade & 46.05 & 33.85 & 61.30 \\
\hline Pareto $11^{\text {th }}$ grade & 50.40 & 38.33 & 65.48 \\
\hline Other $5^{\text {th }}$ grade & 8.52 & 3.78 & 14.44 \\
\hline Other $7^{\text {th }}$ grade & 7.59 & 2.50 & 13.94 \\
\hline Other $\mathbf{9}^{\text {th }}$ grade & 8.12 & 3.08 & 14.42 \\
\hline Other $\mathbf{1 1 ^ { \text { th } }}$ grade & 8.07 & 2.62 & 14.88 \\
\hline \multicolumn{4}{|c|}{ FIRST-ORDER BELIEFS } \\
\hline Nash $5^{\text {th }}$ grade & 34.81 & 51.33 & 14.17 \\
\hline Nash $7^{\text {th }}$ grade & 33.01 & 49.23 & 12.74 \\
\hline Nash $9^{\text {th }}$ grade & 34.83 & 51.92 & 13.46 \\
\hline Nash $11^{\text {th }}$ grade & 34.26 & 51.67 & 12.50 \\
\hline Pareto $5^{\text {th }}$ grade & 57.16 & 46.44 & 70.56 \\
\hline Pareto $7^{\text {th }}$ grade & 59.94 & 48.46 & 74.28 \\
\hline Pareto $\mathbf{9}^{\text {th }}$ grade & 57.05 & 45.19 & 71.88 \\
\hline Pareto $\mathbf{1 1}^{\text {th }}$ grade & 57.14 & 44.76 & 72.62 \\
\hline Other $5^{\text {th }}$ grade & 8.03 & 2.22 & 15.28 \\
\hline Other $7^{\text {th }}$ grade & 7.05 & 2.31 & 12.98 \\
\hline Other $\mathbf{9}^{\text {th }}$ grade & 8.12 & 2.88 & 14.66 \\
\hline Other $11^{\text {th }}$ grade & 8.60 & 3.57 & 14.88 \\
\hline \multicolumn{4}{|c|}{ SECOND-ORDER BELIEFS } \\
\hline Nash $5^{\text {th }}$ grade & 37.90 & 51.33 & $21.11^{*}$ \\
\hline Nash $7^{\text {th }}$ grade & 32.59 & 48.27 & 12.98 \\
\hline Nash $\mathbf{9}^{\text {th }}$ grade & 34.19 & 49.62 & 14.90 \\
\hline Nash $11^{\text {th }}$ grade & 34.26 & 50.48 & 13.99 \\
\hline Pareto $5^{\text {th }}$ grade & 55.31 & 46.00 & 66.94 \\
\hline Pareto $7^{\text {th }}$ grade & 59.30 & 49.04 & 72.12 \\
\hline Pareto $\mathbf{9}^{\text {th }}$ grade & 56.52 & 47.50 & 67.79 \\
\hline Pareto $11^{\text {th }}$ grade & 57.01 & 46.67 & 69.94 \\
\hline Other $5^{\text {th }}$ grade & 6.79 & 2.67 & $11.94 *$ \\
\hline Other $7^{\text {th }}$ grade & 8.12 & 2.69 & 14.90 \\
\hline Other $\mathbf{9}^{\text {th }}$ grade & 9.30 & 2.88 & 17.31 \\
\hline Other $\mathbf{1 1}^{\text {th }}$ grade & 8.73 & 2.86 & 16.07 \\
\hline
\end{tabular}


Table S2: Complexity of the game, choices and beliefs (relative frequencies in \%)

\begin{tabular}{|c|c|c|c|c|c|}
\hline $\begin{array}{l}\text { Complexity (game } \\
\text { type) }^{\mathrm{a}}\end{array}$ & $1 R(D)$ & $2 R(D)$ & $2 R(N D)$ & $3 R(N D)$ & $\infty R(N D)$ \\
\hline \multicolumn{6}{|c|}{ CHOICES } \\
\hline Nash $5^{\text {th }}$ grade & 89.78 & 39.56 & 38.89 & 8.88 & 30.00 \\
\hline Nash $7^{\text {th }}$ grade & 86.15 & 38.08 & 35.58 & 7.69 & 28.37 \\
\hline Nash $\mathbf{9}^{\text {th }}$ grade & 83.46 & 42.69 & 36.54 & 7.69 & 26.44 \\
\hline Nash $11^{\text {th }}$ grade & 81.90 & 36.19 & 28.57 & 8.33 & 20.83 \\
\hline Pareto $5^{\text {th }}$ grade & 6.22 & 56.89 & 61.11 & $42.22 * *$ & 65.56 \\
\hline Pareto $7^{\text {th }}$ grade & 11.15 & 59.62 & 64.42 & 45.19 & 67.31 \\
\hline Pareto $9^{\text {th }}$ grade & 15.00 & 52.69 & 63.46 & 55.77 & 62.98 \\
\hline Pareto $11^{\text {th }}$ grade & 16.19 & 60.48 & 71.43 & 47.62 & 71.43 \\
\hline Other $5^{\text {th }}$ grade & 4.00 & 3.56 & 0.00 & $48.89 * *$ & 4.44 \\
\hline Other $7^{\text {th }}$ grade & 2.69 & 2.31 & 0.00 & 47.12 & 4.33 \\
\hline Other $\mathbf{9}^{\text {th }}$ grade & 1.54 & 4.62 & 0.00 & 36.54 & 10.58 \\
\hline Other $\mathbf{1 1 ^ { \text { th } }}$ grade & 1.90 & 3.33 & 0.00 & 44.05 & 7.74 \\
\hline \multicolumn{6}{|c|}{ FIRST-ORDER BELIEFS } \\
\hline Nash $5^{\text {th }}$ grade & 87.11 & 15.56 & 14.44 & 13.33 & 14.44 \\
\hline Nash $7^{\text {th }}$ grade & 87.69 & 10.77 & 15.38 & 10.58 & 12.50 \\
\hline Nash $9^{\text {th }}$ grade & 86.54 & 17.31 & 15.38 & 7.69 & 15.38 \\
\hline Nash $11^{\text {th }}$ grade & 86.67 & 16.67 & 11.90 & 5.95 & 16.07 \\
\hline Pareto $5^{\text {th }}$ grade & 12.00 & 80.89 & 85.56 & $42.22 *$ & 77.22 \\
\hline Pareto $7^{\text {th }}$ grade & 10.00 & 86.92 & 84.62 & 46.15 & 83.17 \\
\hline Pareto $9^{\text {th }}$ grade & 11.54 & 78.85 & 84.62 & 55.77 & 73.56 \\
\hline Pareto $11^{\text {th }}$ grade & 9.52 & 80.00 & 88.10 & 47.62 & 77.38 \\
\hline Other $5^{\text {th }}$ grade & 0.89 & 3.56 & 0.00 & 44.44 & $8.33 *$ \\
\hline Other $7^{\text {th }}$ grade & 2.31 & 2.31 & 0.00 & 43.27 & 4.33 \\
\hline Other $\mathbf{9}^{\text {th }}$ grade & 1.92 & 3.85 & 0.00 & 36.54 & 11.06 \\
\hline Other $\mathbf{1 1}^{\text {th }}$ grade & 3.81 & 3.33 & 0.00 & 46.43 & 6.55 \\
\hline \multicolumn{6}{|c|}{ SECOND-ORDER BELIEFS } \\
\hline Nash $5^{\text {th }}$ grade & 77.78 & $24.89 *$ & 20.00 & $22.22 * *$ & 21.11 \\
\hline Nash $7^{\text {th }}$ grade & 82.69 & 13.85 & 13.46 & 8.65 & 14.91 \\
\hline Nash $9^{\text {th }}$ grade & 77.69 & 21.54 & 11.54 & 8.65 & 19.71 \\
\hline Nash $11^{\text {th }}$ grade & 85.71 & 15.24 & 9.52 & 8.33 & 19.05 \\
\hline Pareto $5^{\text {th }}$ grade & 18.67 & 73.33 & 80.00 & 44.44 & 71.67 \\
\hline Pareto $7^{\text {th }}$ grade & 15.00 & 83.08 & 86.54 & 46.15 & 77.88 \\
\hline Pareto $9^{\text {th }}$ grade & 20.38 & 74.62 & 88.46 & 50.00 & 66.35 \\
\hline Pareto $\mathbf{1 1}^{\text {th }}$ grade & 11.43 & 81.90 & 90.48 & 45.24 & 72.02 \\
\hline Other $5^{\text {th }}$ grade & 3.56 & 1.78 & 0.00 & $33.33 *$ & 7.22 \\
\hline Other $7^{\text {th }}$ grade & 2.31 & 3.08 & 0.00 & 45.19 & 7.21 \\
\hline Other $\mathbf{9}^{\text {th }}$ grade & 1.92 & 3.85 & 0.00 & 41.35 & 13.94 \\
\hline Other $\mathbf{1 1}^{\text {th }}$ grade & 2.86 & 2.86 & 0.00 & 46.43 & 8.93 \\
\hline
\end{tabular}

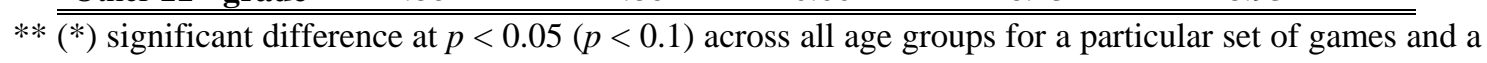
given strategy according to a two-sided Kruskal-Wallis test.

a The columns separate behavior according to (i) the different number of rounds $(\boldsymbol{R})$ of iterated purestrategy dominance a player needs to identify the own equilibrium choice, and (ii) the presence $(\boldsymbol{D})$ or absence (ND) of a dominant strategy in the game. 
Table S3: Percentages of decisions that comply with equilibrium, contingent on game-type

Complexity (game \# for rows // game \# for columns) $5^{\text {th }}$ grade $7^{\text {th }}$ grade $9^{\text {th }}$ grade $11^{\text {th }}$ grade

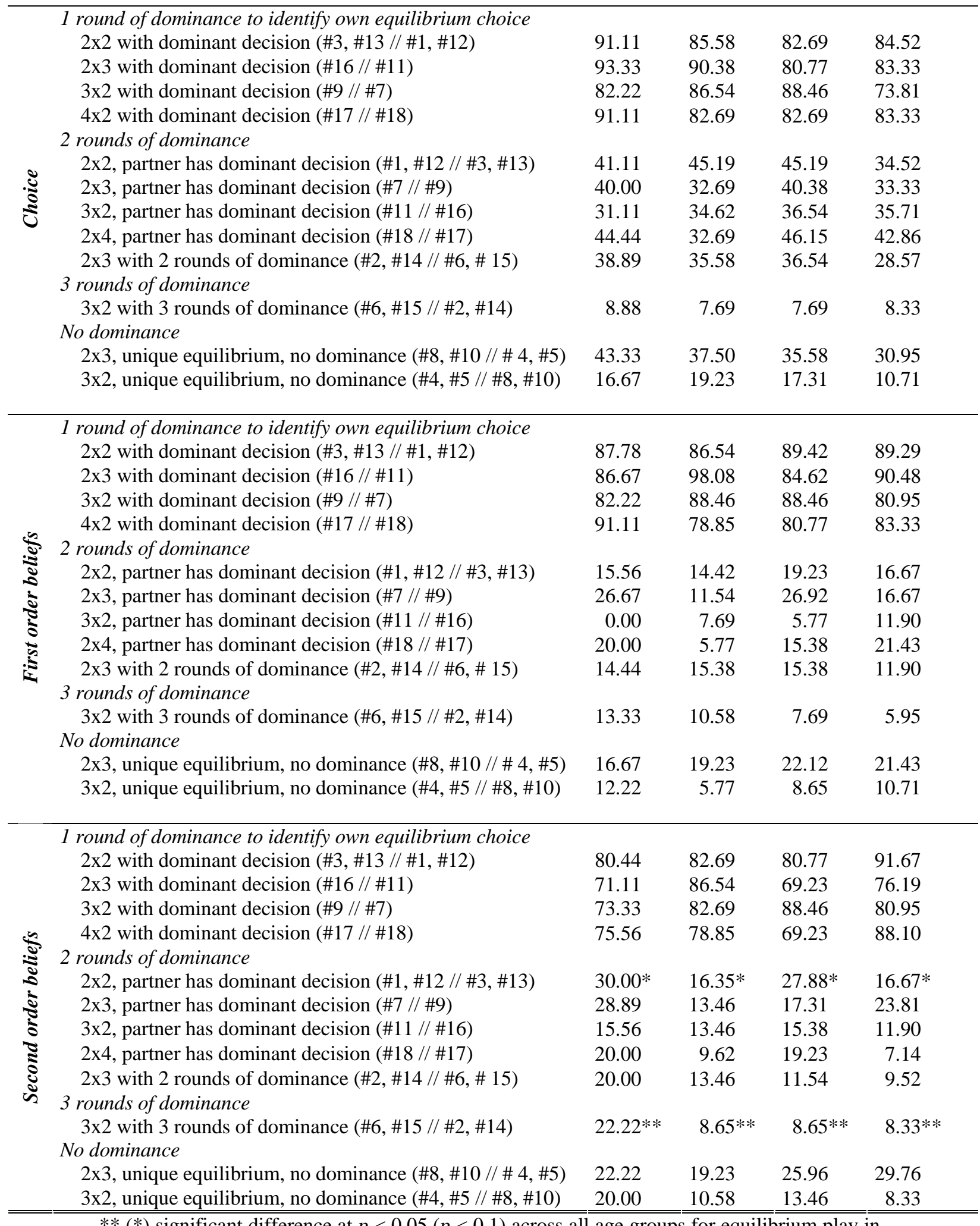

** $\left(^{*}\right)$ significant difference at $p<0.05(p<0.1)$ across all age groups for equilibrium play in a particular set of games according to a two-sided Kruskal-Wallis test. 
Table S4: Consistency of decisions (relative frequency of best reply)

\begin{tabular}{|c|c|c|c|c|}
\hline & & All games & D-games & ND-games \\
\hline $\begin{array}{l}\text { Own consistency } \\
\text { Choice is best reply to first- } \\
\text { order belief }\end{array}$ & $\begin{array}{l}5^{\text {th }} \text { grade } \\
7^{\text {th }} \text { grade } \\
9^{\text {th }} \text { grade } \\
11^{\text {th }} \text { grade } \\
\end{array}$ & $\begin{array}{l}64.44 \\
61.47 \\
64.42 \\
60.85 \\
\end{array}$ & $\begin{array}{l}67.78 \\
64.32 \\
68.27 \\
64.05 \\
\end{array}$ & $\begin{array}{l}60.28 \\
57.93 \\
59.62 \\
56.85 \\
\end{array}$ \\
\hline $\begin{array}{l}\text { Opponent's expected } \\
\text { consistency } \\
\text { First-order belief is best } \\
\text { reply to second-order belief }\end{array}$ & $\begin{array}{l}5^{\text {th }} \text { grade } \\
7^{\text {th }} \text { grade } \\
9^{\text {th }} \text { grade } \\
11^{\text {th }} \text { grade }\end{array}$ & $\begin{array}{l}50.99 \\
51.99 \\
55.98 \\
51.59 \\
\end{array}$ & $\begin{array}{l}55.78 \\
53.42 \\
60.00 \\
55.24 \\
\end{array}$ & $\begin{array}{l}45.00 \\
50.24 \\
50.96 \\
47.02 \\
\end{array}$ \\
\hline
\end{tabular}

a given strategy according to a two-sided Kruskal-Wallis test. 
Table S5: Relative frequency of consistency-types Nash-CON and Max-CON

\begin{tabular}{|c|c|c|c|c|}
\hline \multirow{10}{*}{$\begin{array}{l}\text { Player's } \\
\text { own } \\
\text { consistency }\end{array}$} & & All games & D-games & ND-games \\
\hline & Nash-CON $5^{\text {th }}$ grade & 15.56 & 23.78 & 5.28 \\
\hline & Nash-CON $7^{\text {th }}$ grade & 14.55 & 21.60 & 5.77 \\
\hline & Nash-CON $9^{\text {th }}$ grade & 18.38 & 27.69 & 6.73 \\
\hline & Nash-CON $11^{\text {th }}$ grade & 15.48 & 24.76 & 3.87 \\
\hline & & & & \\
\hline & Max-CON $5^{\text {th }}$ grade & 40.99 & 42.00 & 39.72 \\
\hline & Max-CON $7^{\text {th }}$ grade & 39.77 & 41.37 & 37.74 \\
\hline & Max-CON $9^{\text {th }}$ grade & 38.03 & 37.69 & 38.46 \\
\hline & Max-CON 11 ${ }^{\text {th }}$ grade & 37.70 & 36.43 & 39.29 \\
\hline \multirow{8}{*}{$\begin{array}{l}\text { Expected } \\
\text { consistency } \\
\text { of opponent }\end{array}$} & Nash-CON $5^{\text {th }}$ grade & $10.13^{* *}$ & $14.67 * *$ & 4.44 \\
\hline & Nash-CON $7^{\text {th }}$ grade & 6.22 & 9.32 & 2.40 \\
\hline & Nash-CON 9 ${ }^{\text {th }}$ grade & 11.22 & 16.92 & 4.09 \\
\hline & Nash-CON $11^{\text {th }}$ grade & 8.99 & 12.86 & 4.17 \\
\hline & Max-CON $5^{\text {th }}$ grade & 37.90 & 39.56 & 35.83 \\
\hline & Max-CON $7^{\text {th }}$ grade & 42.34 & 42.54 & 42.07 \\
\hline & Max-CON $9^{\text {th }}$ grade & 40.92 & 40.58 & 41.35 \\
\hline & Max-CON $11^{\text {th }}$ grade & 39.29 & 40.71 & 37.50 \\
\hline
\end{tabular}

** (*) significant difference at $p<0.05(p<0.1)$ across all age groups for a particular set of games and a given strategy according to a two-sided Kruskal-Wallis test. 